\title{
SARS-CoV-2 Serological Survey of Cats in China before and after the Pandemic
}

\author{
Junhua Deng ${ }^{1} \cdot$ Yuxiu Liu ${ }^{2} \cdot$ Chunyan Sun ${ }^{2} \cdot$ Jingjing Bai ${ }^{1} \cdot$ Jie Sun $^{1} \cdot$ Liying Hao $^{1} \cdot{\text { Xiangdong } \mathrm{Li}^{3,4}}_{(\mathbb{D}} \cdot$ \\ Kegong Tian ${ }^{1,2}$
}

Received: 12 June 2020 / Accepted: 3 August 2020 / Published online: 1 September 2020

(c) Wuhan Institute of Virology, CAS 2020

Dear Editor,

SARS-CoV-2 or COVID-19 has become pandemic and spread to more than 200 countries with over 24 million human infected cases (WHO 2020). The origin of SARSCoV-2 remains unknown, though bat, pangolin, and snake were reported to be the potential animal reservoirs (Ji et al. 2020; Ward et al. 2020; Chen et al. 2020). Companion animals including dogs and cats were recent sporadically reported to be infected by SARS-CoV-2 with or without clinical symptoms (Li 2020a, b; Sailleau et al. 2020). Recently, both Chinese and American groups reported that cats were highly susceptible to SARS-CoV-2 after artificial inoculation and could spread the virus via respiratory droplets (Shi et al. 2020; Bosco-Lauth et al. 2020). Coincidently, Zhang et al. (2020) reported that 15 of 102 $(14.7 \%)$ cats in Wuhan City during SARS-CoV-2 outbreak showed serological positive using an in-house indirect enzyme linked immunosorbent assay (ELISA) (Zhang et al. 2020). These reports raise a huge public concern as the infected cats could play a role in transmission of SARS-

Junhua Deng and Yuxiu Liu have contributed equally to this work.

Kegong Tian

tiankg@263.net

$\triangle$ Xiangdong Li

007352@yzu.edu.cn

1 Luoyang Putai Biotechnology Co., Ltd, Luoyang 471003, China

2 National Research Center for Veterinary Medicine, Luoyang 471003, China

3 Jiangsu Co-innovation Center for Prevention and Control of Important Animal Infectious Diseases and Zoonoses, College of Veterinary Medicine, Yangzhou University, Yangzhou 225009, China

4 Joint International Research Laboratory of Agriculture and Agri-Product Safety, The Ministry of Education of China, Yangzhou University, Yangzhou 225009, China
CoV-2. The high percentage of seropositivity of cats in Wuhan, the epicentre of the SARS-CoV-2 epidemic, could be due to the large number of infected human cases (more than 14 folds than that in other cities) (Table 1) where cats may have been more frequently exposed to SARS-CoV-2 patients or contaminated environment. As yet, SARS-CoV2 serological prevalence of cats in other Chinese cities remains unknown. Therefore, a serological survey including more cities with numbers of SARS-CoV-2 human cases in China will be valuable for elucidating the role of cats in transmission of the viruses and relieve public concerns. In this study, 630 cat serum samples collected before November 2019 and 423 cat serum samples collected during SARS-CoV-2 outbreak (from February 2020 to April 2020) in 20 cities in China for detecting the prevalence of SARS-CoV-2 specific antibodies.

In a recent study, we conducted a survey of SARS-CoV2 in 35 different species of animals, in which 87 cats including 66 pet cats and 21 stray cats were tested serological negative using a commercial ELISA Kit (Deng et al. 2020). There were no seropositive cat samples from Wuhan City in our study, which is totally different from the high serological prevalence of cats in Wuhan in Zhang's report. To further explore seropositivity among cats in other cities, 1053 cats were sampled before and after the SARS-CoV-2 outbreak from 20 cities of different provinces in China where the SARS-CoV-2 epidemic situations were classified into $\mathrm{A}, \mathrm{B}, \mathrm{C}$, and $\mathrm{D}$ according to official reported numbers of human cases (Table 1). All cat serum samples were collected from pet hospitals. SARSCoV-2 specific antibodies were detected using ELISA as previously described (Deng et al. 2020).

630 cat serum samples collected before the outbreak of SARS-CoV-2 were tested to be serologically negative, which is consistent with Zhang's report (Zhang et al. 2020). To our surprise, 423 cat serum samples (including 48 samples in Wuhan and 42 samples in other 3 cities of Hubei Province) collected during SARS-CoV-2 pandemic 
Table 1 Detailed information about the cat serum samples in different cities and ELISA results.

\begin{tabular}{|c|c|c|c|c|c|c|}
\hline \multirow[t]{2}{*}{ Class } & \multirow{2}{*}{$\begin{array}{l}\text { Provinces } \\
\text { (reported human cases) }\end{array}$} & \multirow[t]{2}{*}{ City } & \multirow{2}{*}{$\begin{array}{l}\text { Reported } \\
\text { human cases }\end{array}$} & \multicolumn{2}{|l|}{ Cat numbers } & \multirow{2}{*}{$\begin{array}{l}\text { ELISA results } \\
\left(\mathrm{OD}_{450} \text { readout }\right)^{\mathrm{a}}\end{array}$} \\
\hline & & & & Before Nov 2019 & After Nov 2019 & \\
\hline \multirow[t]{4}{*}{ A } & \multirow[t]{4}{*}{ Hubei (68128) } & Wuhan & 50333 & 0 & 48 & $-(0.005$ to 0.195$)$ \\
\hline & & Xiaogan & 3518 & 0 & 16 & $-(0.007$ to 0.124$)$ \\
\hline & & Jingmen & 928 & 0 & 20 & $-(0.005$ to 0.132$)$ \\
\hline & & Huanggang & 2907 & 0 & 6 & $-(0.005$ to 0.138$)$ \\
\hline \multirow[t]{4}{*}{ B } & \multirow[t]{2}{*}{ Henan (1276) } & ZhengZhou & 157 & 23 & 9 & $-(0.006$ to 0.085$)$ \\
\hline & & Luoyang & 31 & 92 & 26 & $-(0.009$ to 0.125$)$ \\
\hline & \multirow[t]{2}{*}{ Guangdong (1579) } & Guangzhou & 499 & 0 & 89 & $-(0.005$ to 0.790$)$ \\
\hline & & Shenzhen & 460 & 0 & 4 & $-(0.005$ to 0.013$)$ \\
\hline \multirow[t]{7}{*}{$\mathrm{C}$} & Heilongjiang (892) & Harbin & 224 & 7 & 10 & $-(0.007$ to 0.034$)$ \\
\hline & Beijing (593) & Beijing & 593 & 145 & 37 & $-(0.005$ to 0.101$)$ \\
\hline & Sichuan (561) & Chengdu & 166 & 0 & 9 & $-(0.007$ to 0.078$)$ \\
\hline & Chongqing (579) & Chongqing & 579 & 17 & 10 & $-(0.005$ to 0.081$)$ \\
\hline & \multirow[t]{2}{*}{ Shandong (787) } & Qingdao & 65 & 5 & 5 & $-(0.005$ to 0.023$)$ \\
\hline & & Yantai & 47 & 0 & 9 & $-(0.005$ to 0.100$)$ \\
\hline & Anhui (991) & Hefei & 174 & 0 & 6 & $-(0.007$ to 0.039$)$ \\
\hline \multirow[t]{5}{*}{$\mathrm{D}$} & Tianjin (189) & Tianjin & 189 & 249 & 33 & $-(0.005$ to 0.144$)$ \\
\hline & Jilin (102) & Changchun & 47 & 3 & 32 & $-(0.005$ to 0.116$)$ \\
\hline & Hainan (168) & Haikou & 39 & 89 & 15 & $-(0.005$ to 0.097$)$ \\
\hline & Guizhou (147) & Guiyang & 36 & 0 & 14 & $-(0.005$ to 0.195$)$ \\
\hline & Yunnan (184) & Kunming & 53 & 0 & 25 & $-(0.005$ to 0.186$)$ \\
\hline Total & 14 & 20 & 61045 & 630 & 423 & - \\
\hline
\end{tabular}

The cutoff was set as $0.26+$ the mean value of $\mathrm{OD}_{450}$ of negative controls according to the manufacture's manual.

${ }^{\mathrm{a}} \mathrm{The} \mathrm{OD}_{450}$ readout of positive controls ranged from 0.582 to 0.722 .

were also serologically negative to SARS-CoV-2 (Table 1). To confirm this result, a real-time PCR specific for SARS-CoV-2 recommended by Chinese Center for Disease Control and Prevention was also applied to all 1053 samples and the results were consistent with the serologic test (Deng et al. 2020). The discrepancy of results between the two research groups could be due to the source of cat samples since all of our samples were collected from pet hospitals. Besides, a SARS-CoV-2 double-antigen sandwich ELISA based on S1 protein of the virus was applied in our study. The potential cross-reaction with other coronavirus including infectious bronchitis virus (IBV), porcine epidemic diarrhea virus (PEDV), porcine transmissible gastroenteritis virus (TGEV), porcine deltacoronavirus (PDCoV), mouse hepatitis virus (MHV) and rat coronavirus (RCV) were tested with corresponding positive serum samples were evaluated in our study. The results showed that it has good specificity without crossreaction with other coronaviruses from different animal species. By contrast, an indirect ELISA base on virus receptor-binding domain (BRD) protein were used in Zhang's study (Zhang et al. 2020). The indirect ELISA showed good specificity since it has no serological cross- reactivity between the SARS-CoV-2 and type I or II feline infectious peritonitis virus (FIPV).

Both Chinese and American research groups individually performed the artificial inoculation of SARS-CoV-2 to cats of different ages and proved cats were susceptible to SARS-CoV-2 (Shi et al. 2020; Bosco-Lauth et al. 2020). In their study, no clinical symptoms were observed after infection for adult cats. By contrast, juvenile cats (70-day to 3 -month old) died at 3 days post-inoculation with severe histological lesions in the nasal and tracheal mucosa epithelium and lungs. However, the experimentally infected cats only had viral replications in their upper airways but not in the lower airways or other organs even with a high dose of virus ( $10^{5}$ plaque-forming units) inoculation. In this study, no minimum infection dose was reported, which will provide valuable information to evaluate the virus load in natural environment where cats may get infected.

It is interesting to note that one Belgium cat was reported to be infected by her SARS-CoV-2 positive owner and showed hard breathing, vomiting, and diarrhea. Among the 15 SARS-CoV-2 serologically positive cats in Zhang's report, the owners of 3 cats coincidently were confirmed to 
be SARS-CoV-2 positive (Zhang et al. 2020). Besides pet cats, one tiger and five lions were reported to be infected with SARS-CoV-2 in the Bronx zoo, USA, and infection was assumed to be caused by a SARS-CoV-2 positive zoo employee (Brownlie and Sibley 2020). Collectively, the above results demonstrated that cats can be infected with SARS-CoV-2 only by close contact with patients who were actively shedding the virus or the contaminated environments where the virus titer was relatively high. However, the reverse transmission from cats to human in natural condition is not yet known. As for the other species of animals for passing SARS-CoV-2 to human was not reported except for the minks in Netherlands (Oreshkova et al. 2020).

The SARS-CoV-2 retrospective survey among cats is important to explain the role of cats play in the transmission of the virus, since cats could be infected by SARSCoV-2 without clinical symptoms and have a narrow window for virus shedding. In this case, molecular techniques such as qRT-PCR may lead to false negative results. Under this circumstances, serological diagnosis result is more useful since the SARS-CoV-2 specific antibodies in cats could be detected during a long period of time after infection. The serologically negative result of 1053 cats from 20 cities in our study indicates that cats play a limited role in transmission during SARS-CoV-2 pandemic and as the social distancing animals the transmission of SARSCoV-2 among cat populations could be minimum. However, this preliminary conclusion was made based on a relative limited number of cat serum samples. A large number of cat populations should be needed for further investigation to confirm the above conclusion.

Acknowledgements This research was supported by Luoyang SARSCoV-2 epidemic prevention and control emergency response technology research project (Prof. Kegong Tian), and the Project of the Priority Academic Program Development of Jiangsu Higher Education Institutions (PAPD) and Ten-thousand Talents Program (Prof. Xiangdong Li).

\section{Compliance with Ethical Standards}

Conflict of interest The authors declare that they have no conflict of interest.
Animal and Human Rights Statement This study was approved by the Animal Care and Ethics Committee of National Research Center for Veterinary Medicine with IACUC Number 2020001.

\section{References}

Bosco-Lauth AM, Hartwig AE, Porter SM, Gordy PW, Nehring M, Byas AD, VandeWoude S, Ragan IK, Maison RM, Bowen RA (2020) Pathogenesis, transmission and response to re-exposure of SARS-CoV-2 in domestic cats. BioRxiv. https://doi.org/10. $1101 / 2020.05 .28 .120998$

Brownlie J, Sibley D (2020) What can animal coronaviruses tell us about emerging human coronaviruses? Vet Rec 186:446-448

Chen N, Li X, Li S, Xiao Y, Ye M, Yan X (2020) How related is SARS-CoV-2 to other coronaviruses? Vet Rec 186:496

Deng J, Jin Y, Liu Y, Sun J, Hao L, Bai J, Huang T, Lin D, Tian K (2020) Serological survey of SARS-CoV-2 for experimental, domestic, companion and wild animals excludes intermediate hosts of 35 different species of animals. Transbound Emerg Dis 67:1745-1749

Ji W, Wang W, Zhao X, Zai J, Li X (2020) Cross-species transmission of the newly identified coronavirus 2019-ncov. J Med Virol $92: 433-440$

Li X (2020a) Can cats become infected with covid-19? Vet Rec $186: 457-458$

Li X (2020b) Cats under the shadow of the sars-cov-2 pandemic. Transbound Emerg Dis 67:1416-1417

Oreshkova N, Molenaar R, Vreman S, Harders F, Munnink B, Hakzevan der Honing R, Gerhards N, Tolsma P, Bouwstra R, Sikkema R, Tacken M, Rooij M, Weesendorp E, Engelsma M, Bruschke C, Lidwien A, Koopmans M, Hm van der Poel W, Stegeman A (2020) SARS-CoV-2 infection in farmed minks, the Netherlands, April and May 2020. Euro Surveill. https://doi.org/10.2807/ 1560-7917.ES.2020.25.23.2001005

Sailleau C, Dumarest M, Vanhomwegen J, Delaplace M, Caro V, Kwasiborski A, Hourdel V, Chevaillier P, Barbarino A, Comtet L, Pourquier P, Klonjkowski B, Manuguerra JC, Zientara S, Le Poder S (2020) First detection and genome sequencing of SARS$\mathrm{CoV}-2$ in an infected cat in France. Transbound Emerg Dis. https://doi.org/10.1111/tbed.13659

Shi J, Wen Z, Zhong G, Yang H, Wang C, Huang B, Liu R, He X, Shuai L, Sun Z, Zhao Y, Liu P, Liang L, Cui P, Wang J, Zhang X, Guan Y, Tan W, Wu G, Chen H, Bu Z (2020) Susceptibility of ferrets, cats, dogs, and other domesticated animals to sarscoronavirus 2. Science 368:1016-1020

Ward MP, Li X, Tian K (2020) Novel coronavirus 2019, an emerging public health emergency. Transbound Emerg Dis 67:469-470

Zhang QZ, Zhang HJ, Huang K, Yang Y, Hui XF, Jin ML (2020) SARS-CoV-2 neutralizing serum antibodies in cats: a serological investigation. BioRxiv. https://doi.org/10.1101/2020.04.01. 021196 